\title{
Pengelompokan Titik Wilayah di Provinsi Daerah Istimewa Yogyakarta Berdasarkan Kualitas Udara Menggunakan Algoritma Fuzzy C-Means
}

Adrian Firmansyah,

Politeknik Statistika STIS

Aprilia Lutviana Dewi,

Politeknik Statistika STIS

Emalia Septiani Hirma,

Politeknik Statistika STIS

M. Bagus Adji Briliyanto,

Politeknik Statistika STIS

Muti Nurjannah,

Politeknik Statistika STIS

Rani Nooraeni

Politeknik Statistika STIS, raninoor@stis.ac.id

ABSTRAK, Salah satu target SDGs adalah menangani permasalahan pencemaran udara, WHO menyebutkan bahwa pencemaran udara merupakan risiko gangguan kesehatan terbesar di dunia. Diperkirakan terdapat sekitar 6,5 juta orang meninggal tiap tahun akibat paparan polusi udara. Provinsi DIY merupakan salah satu daerah yang masih memiliki masalah pencemaran lingkungan, mobilitas manusia yang tinggi dengan bertambahnya pengguna kendaraan bermotor membuat pencemaran semakin meningkat. Selain itu, konsumsi energi dan aktivitas industri yang tidak terkendali terutama di daerah perkotaan juga ikut memperburuk kualitas udara. Penelitian ini bertujuan untuk mengelompokkan wilayah-wilayah di Provinsi DIY berdasarkan data kualitas udara yang terekam pada 75 titik amatan agar diperoleh gambaran umum karakteristik wilayah tertentu dengan masalah pencemaran udara spesifik meliputi gas pencemar $\mathrm{CO}, \mathrm{SO}_{2}, \mathrm{NO}_{2}$, dan $\mathrm{O}_{3}$. Data yang digunakan merupakan data sekunder dari Kementerian Lingkungan Hidup Provinsi DIY, sedangkan metode yang digunakan adalah fuzzy c-means clustering. Hasilnya, dari profile data sebelum dilakukan pengelompokan diperoleh kadar $\mathrm{CO}, \mathrm{SO}_{2}, \mathrm{NO}_{2}$, dan $\mathrm{O}_{3}$ terendah berada pada titik-titik wilayah permukiman dan tertinggi berada pada titik perempatan jalan, training camp, kampus fakultas teknik, dan industri dan hasil dari perbandingan clustering validity index terbentuk sebanyak 2 kelompok. Kelompok 1 memiliki titik tengah kadar pencemar gas $\mathrm{NO}_{2}, \mathrm{SO}_{2}, \mathrm{CO}$, dan $\mathrm{O}_{3}$ yang lebih tinggi dibandingkan kelompok 2. Kelompok 1 terdiri atas 45 anggota, dimana sebagian besar kelompok ini merupakan titik industri, persimpangan jalan, serta pusat keramaian. Sedangkan kelompok 2 terdiri atas 30 anggota, dimana sebagian besar kelompok ini merupakan titik permukiman.

Kata Kunci: pencemaran udara, kualitas udara, fuzzy cmeans clustering

\section{PENDAHULUAN}

Suistainable Development Goals (SDGs) merupakan rencana pembangunan global terdiri dari 17 tujuan dan 169 target yang dirumuskan oleh United Nations (UN) yang berlaku sejak tahun 2016 hingga 2030. Salah satu target SDGs di antaranya adalah menangani permasalahan pencemaran udara yang berdampak pada kesehatan manusia. WHO menyebutkan bahwa pencemaran udara merupakan risiko gangguan kesehatan terbesar di dunia. Terdapat sekitar 6,5 juta orang meninggal tiap tahun akibat paparan polusi udara. Adanya berbagai pembangunan seperti pembangunan pusat industri, transportasi, dan infrastruktur menjadi pemicu terjadi perubahan kualitas udara. Perubahan itu 
dikarenakan adanya zat pencemar berbentuk partikel kecil dan gas-gas tertentu yang terkandung dalam udara. Bahan pencemar gas primer terdiri dari karbon monoksida (CO), berbagai senyawa hidrokarbon, berbagai oksida nitrogen $\left(\mathrm{NO}_{\mathrm{x}}\right)$, dan sulfur $\left(\mathrm{SO}_{\mathrm{x}}\right)$ [1]. Pencemar ini bersumber dari aktivitas kendaraan, industri, PLTU, dan pembakaran sampah. Bahaya yang ditimbulkan dapat berupa gangguan paru-paru dan kardiovaskular pada manusia serta kematian tanaman dan hewan. Sedangkan bahan pencemar sekunder berbahaya yang diperoleh dari reaksi fotokimia pencemar gas primer yaitu ozon $\left(\mathrm{O}_{3}\right)$.

Konsumsi energi dan aktivitas industri yang tidak terkendali terutama di daerah perkotaan juga ikut memperburuk kualitas udara. Indeks Kualitas Udara (IKU) merupakan nilai yang menunjukkan mutu kebaikan atau kualitas udara dengan nilai ideal 100, yaitu menggambarkan kualitas udara terbaik. IKU di provinsi Daerah Istimewa Yogyakarta (DIY) tahun 2018 sebesar 84,25 sudah mencapai target Rencana Strategis (Renstra) tahun 2018 sebesar 83,00. Namun angka tersebut mengalami penurunan dibandingkan IKU DIY pada tahun 2017 sebesar 88,08 [2], [3]. Kehidupan sehari-hari melibatkan berbagai peralatan modern turut serta dalam mencemari udara. Pembangkit listrik sebagai penyalur energi ke setiap rumah untuk dimanfaatkan sebagai penerangan, daya televisi, daya $\mathrm{AC}$, dan peralatan listrik lainnya. Bahan bakar untuk pembangkit di Indonesia sebagian besar berupa batu bara dan minyak yang menimbulkan residu atau limbah sisa sebagai kontributor emisi gas. Disamping itu, kegiatan sehari-hari seperti pembakaran sampah terbuka juga ikut berperan dalam pencemaran udara [4]. Provinsi DIY merupakan daerah yang padat penduduk. Pada tahun 2015 provinsi DIY merupakan provinsi terpadat keempat di Indonesia sebesar $1174 \mathrm{jiwa} / \mathrm{km}^{2}$ [5]. Disamping itu, adanya peningkatan jumlah wisatawan berimplikasi pada kepadatan penduduk di provinsi DIY yang juga semakin bertambah, terutama disaat liburan [6]. Peningkatan kepadatan penduduk akan mempengaruhi kualitas udara di suatu wilayah. Kepadatan penduduk secara positif dan signifikan mempengaruhi emisi udara [7]. Mobilitas manusia yang tinggi dengan bertambahnya pengguna kendaraan bermotor membuat pencemaran juga akan meningkat [8].

Salah satu kontributor utama pencemaran udara di provinsi DIY yaitu kendaraan bermotor. Selain itu, kurangnya akses dalam penggunaan transportasi umum juga menyebabkan pengguna kendaraan pribadi terus meningkat. Pertumbuhan jumlah kendaraan bermotor di provinsi DIY selalu meningkat setiap tahunnya $[9,10,11]$.

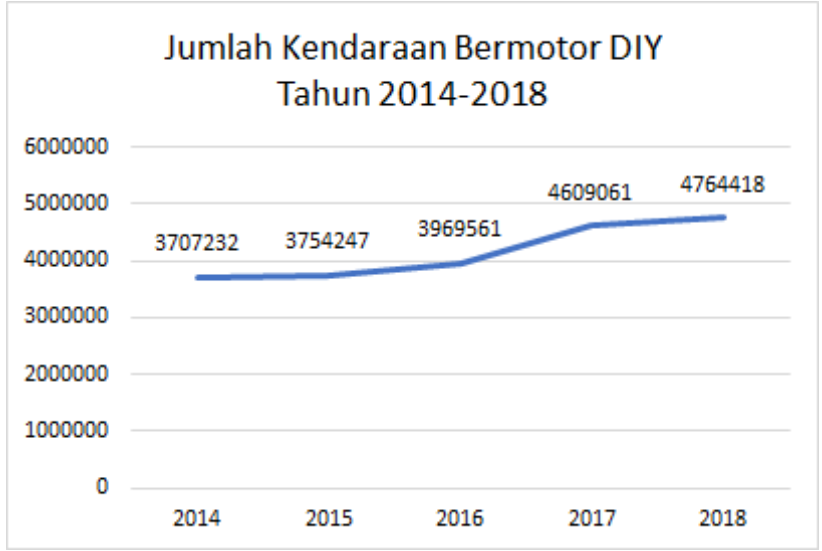

Sumber: Statistik Transportasi Darat, Badan Pusat Statistik (diolah)

\section{Grafik 1. Jumlah Kendaraan Bermotor di Daerah Istimewa Yogyakarta Tahun 2014-2018}

Permasalahan lingkungan provinsi DIY juga semakin kompleks dengan keberadaan industri rumahan. Provinsi DIY dikenal sebagai kota wisata yang terdapat banyak industri-industri rumah tangga kreatif seperti industri pembatikan, industri padat karya, dan industri lainnya. Industri pembatikan provinsi DIY terindikasi adanya kontaminasi dari karbon monoksida pada ruang kerja [12]. Selain itu, terdapat pengembangan kawasan untuk lokasi industri di wilayah Bantul juga menimbulkan permasalahan 
yang dirasakan masyarakat sekitar. Seperti permasalahan limbah udara pada cerobong asap pabrik aspal di Tegalyoso, Piyungan [13].

Berbagai permasalahan lingkungan dari provinsi DIY di atas menunjukkan adanya keragaman sumber pencemaran udara dengan level berbahaya yang beragam juga. Oleh sebab itu, perlu dilakukan penanganan yang beragam sesuai kondisi pencemaran di wilayah yang bersangkutan. Untuk itu, peneliti ingin melakukan pengelompokan wilayah berdasarkan data kualitas udara yang terekam pada 75 titik amatan yang tersebar di provinsi DIY pada tahun 2018 dengan menggunakan metode pengelompokan lebih tepatnya fuzzy c-means clustering. Data yang digunakan bersumber dari data Kementerian Lingkungan Hidup Provinsi DIY tahun 2018.

Tujuan penelitian ini yaitu

1) Mengetahui gambaran umum kualitas udara ambien menurut jenis polutan $\mathrm{CO}, \mathrm{SO}_{2}, \mathrm{NO}_{2}$, dan $\mathrm{O}_{3}$

2) Mengelompokkan wilayah-wilayah di provinsi DIY agar diperoleh gambaran umum karakteristik wilayah tertentu dengan masalah pencemaran udara spesifik meliputi gas pencemar $\mathrm{CO}, \mathrm{SO}_{2}, \mathrm{NO}_{2}$, dan $\mathrm{O}_{3}$. Pengelompokan ini akan mempermudah penanganan masalah pencemaran udara di wilayah-wilayah provinsi DIY sesuai sumber pencemaran

\section{TINJAUAN PUSTAKA}

\section{CLUSTERING}

Clustering merupakan salah satu metode unsupervised pada data mining. Metode pengelompokan dalam data mining berbeda dengan metode konvensional yang biasa digunakan untuk pengelompokan [18]. Metode pengelompokan ini banyak jenisnya salah satunya Fuzzy Clustering.

\section{FUZZY C-MEANS CLUSTERING}

Fuzzy C-Means (FCM) merupakan salah satu teknik fuzzy clustering (pengelompokan fuzzy) yang paling sederhana. Dun (1973) mengusulkan teknik ini yang kemudian disempurnakan oleh Bezdek (1981). Fungsi objektif FCM :

$J_{m}(U, V)=\sum_{i=1}^{n} \sum_{k=1}^{K} u_{i k}^{m}\left\|x_{i}-v_{k}\right\|^{2} ; \quad v_{k}=$ $\frac{\sum_{i=1}^{n} u_{i k}^{m} x_{i}}{\sum_{i=1}^{n} u_{i k}^{m}}$

$\mathrm{U}$ : membership matrix yang berisikan derajat keanggotaan $\left(u_{i k}\right)$

$\mathrm{V}$ : centroid matrix yang berisikan vektor pusat kelompok $\left(v_{k}\right)$

$u_{i k}$ : derajat keanggotaan antara data ke-i dengan kelompok ke-k

$v_{k}$ : vektor yang merupakan pusat kelompok ke-k $x_{i}$ : vektor yang berisi data pada observasi ke-i $\mathrm{m}$ : fuzzifier/parameter ke-fuzzy-an

Nilai m merupakan parameter yang mengontrol kemungkinan adanya irisan antar kelompok yang terbentuk. Tidak terdapat aturan khusus nilai yang tepat untuk m. Bezdek et al. (1984) merekomendasikan nilai $\mathrm{m}$ yang berkisar 1.5 hingga 3. Sedangkan jika terdapat outlier $\mathrm{Wu}$ (2012) merekomendasikan m berkisar 1.5 hingga 4 untuk memberikan efek robust pada data yang mengandung outlier. Nilai $m$ ini ikut memengaruhi ketahanan FCM terhadap noise dan pencilan [16]

Kelebihan dari FCM yaitu memperbaiki pusat kelompok dan derajat keanggotaan tiap-tiap titik data secara berulang sehingga dapat dilihat bahwa pusat kelompok akan bergerak menuju ke lokasi yang tepat. Selain itu, metode kelompok ini juga memiliki akurasi yang tinggi dan waktu komputasi yang cepat. Dibandingkan dengan kmeans, algoritma c-means lebih unggul dalam mengatasi data outlier. Saat clustering dengan $c$ means, data outlier akan bergabung menjadi satu kelompok dengan pusat kelompok, sedangkan $k$ means, data outlier membentuk kelompok 
tersendiri. Ini terjadi karena FCM memiliki derajat keanggotaan untuk mengelompokkan ke dalam kelompok yang semestinya [17].

\section{VALIDITAS CLUSTERING}

\section{1) Partition Coefficient Index (PCI)}

Partition Coefficient Index (PCI) atau indeks koefisien partisi merupakan fungsi validitas Fuzzy C-Means pertama yang diusulkan oleh Bezdek 1974. PCI mengukur jumlah overlapping antar kelompok yang biasa mengandung informasi geometrik. Persamaan PCI sebagai berikut:

$$
P C I=\frac{1}{N} \sum_{i=1}^{c} \sum_{k=1}^{N} u_{i k}^{2}
$$

Di mana $N$ adalah objek penelitian, sedangkan $c$ adalah banyak kelompok dan $u_{i k}$ adalah nilai keanggotaan objek ke-k dengan pusat kelompok ke-i. PCI berada dalam rentang $\frac{1}{c} \leq P C I \leq 1$. Jika mendekati 1 maka kelompok tersebut dapat dikatakan optimal atau menghasilkan kinerja pengelompokan terbaik untuk data set tersebut [20].

\section{2) Modified Partition Coefficient Index} (MPCI)

Modified Partition Coefficient Index (MPCI) adalah salah satu fungsi validitas dengan penyempurnaan dari PCI dan PEI yang digagaskan oleh Dave (1996), untuk mengatasi kekurangan PCI dan PEI yang mana memiliki kecenderungan berubah secara monotonic dengan seiring dengan berubahnya nilai c. Kemudian MPCI yang didapat berada pada $0 \leq$ $M P C I \leq 1$, jika mendekati 1 maka kelompok tersebut dapat dikatakan optimal atau terbaik. Persamaan MPCI sebagai berikut:

$$
M P C I=1-\frac{c}{c-1}(1-P C I)
$$

Di mana $c$ adalah banyak kelompok dan PCI adalah Partition Coefficient Index. [21]

\section{3) Partition Enthropy Index (PEI)}

Partition Enthropy Index (PEI) diusulkan oleh James C. Bezdek pada tahun 1974 digunakan untuk mengevaluasi keteracakan data di dalam kelompok [22]. Indeks validitas ini didefinisikan dalam persamaan sebagai berikut:

$$
P E I=-\frac{1}{N}\left(\sum_{i=1}^{N} \sum_{j=1}^{K} u_{i j} \times \log _{2} u_{i j}\right)
$$

Pada umumnya kelompok optimal akan diperoleh jika nilai yang didapat semakin kecil (mendekati 0). Nilai yang semakin kecil (mendekati 0) memiliki arti bahwa kualitas kelompok yang diperoleh semakin baik [23].

\section{4) Fuzzy Silhouete Index}

Silhouette Index (SI) dapat digunakan untuk memvalidasi baik sebuah data, kelompok tunggal (satu kelompok dari sejumlah kelompok) atau bahkan keseluruhan kelompok. Indeks ini menghitung rata-rata nilai setiap titik pada himpunan data. Perhitungan nilai setiap titik adalah selisih nilai separation dan compactness yang dibagi dengan maksimum antara keduanya. Jumlah kelompok terbaik dipilih dengan nilai Silhouette yang paling mendekati 1 ( Rosseeuw, 1987). Misalkan terdapat $N$ buah titik pada suatu himpunan data, terdapat pula di dalamnya kelompok $\mathrm{p}$ dan kelompok $\mathrm{q}$ dengan $\mathrm{x}_{\mathrm{i}}$ adalah titik pusat $p$ dan $y_{j}$ merupakan titik pada kelompok $q$, sehingga $a_{p, i}$ adalah rata-rata jarak titik $x_{i}$ ke tiap titik pada kelompok $p$ dan $d_{q, i}$ merupakan rata-rata jarak titik $x_{i}$ ke tiap titik di kelompok q. Rumus indeks Silhouette adalah sebagai berikut.

$$
\begin{aligned}
S I L= & \frac{1}{N} \sum_{i=0}^{N} s_{x_{i}} \\
& s_{x_{i}}=\frac{\left(b_{q, i}-a_{p, i}\right)}{\max \left\{a_{p, i}, b_{q, i}\right\}}, p \neq q \\
b_{q, i}= & \min d_{q, i} ; q=1,2, \ldots, k \\
& d_{q, i}=\frac{1}{n_{q}} \sum_{i=1}^{n_{q}} d\left(x_{i}, y_{j}\right) \\
a_{p, i}= & \frac{1}{n_{p}} \sum_{k=1}^{n_{p}} d\left(x_{i}, x_{k}\right)
\end{aligned}
$$




\section{5) Xie Beni Index (XBI)}

Xie Beni Index (XBI) ditemukan oleh Xie dan Beni dan pertama kali dikemukakan pada tahun 1991. Kriteria dalam pengukuran validitas suatu kelompok terdiri dari ukuran kedekatan antar anggota tiap kelompok (compactness) dan ukuran keterpisahan antar kelompok (separation). Ukuran validitas kelompok menggunakan XBI dirumuskan sebagai berikut:

$$
X B I=\frac{\sum_{i=1}^{c} \sum_{j=1}^{n} \mu_{i k}{ }^{w *}\left\|V_{i}-X_{j}\right\|^{2}}{n * \min _{i, j}\left\|V_{i}-V_{j}\right\|^{2}}
$$

Dengan $\mathrm{c}=$ banyak kelompok, $\mathrm{n}=$ banyak objek yang dikelompokkan, $\mu_{i k}=$ derajat keanggotaan fuzzy, $\mathrm{w}=$ pangkat pembobot (fuzzifier), $n *$ $\min _{i, j}\left\|V_{i}-V_{j}\right\|^{2}=$ jarak minimum antara pusat kelompok dan $v_{i}$ dan $v_{j}$. [25].

\section{METODOLOGI}

\section{Variabel Penelitian dan Sumber Data}

Penelitian ini menggunakan data sekunder yang berasal dari database Dinas Lingkungan Hidup Provinsi DIY tahun 2018. Data tersebut diambil dari 75 titik amatan yang diukur menggunakan alat pengukur konsentrasi zat pencemar udara yang tersebar di seluruh provinsi DIY. Namun data tersebut memiliki keterbatasan. Sebagian besar titik amatan berada di Kota Yogyakarta dan sekitarnya (dapat dilihat pada Gambar 4). Sementara sebagian kecil titik amatan menyebar di Kabupaten Bantul, Kabupaten Sleman, Kabupaten Kulon Progo, dan Kabupaten Gunung Kidul. Adapun variabel yang dianalisis dalam penelitian ini meliputi kadar gas pencemar $\mathrm{CO}$, $\mathrm{SO}_{2}, \mathrm{NO}_{2}$, dan $\mathrm{O}_{3}$ di setiap titik amatan dengan satuan $\mu \mathrm{g} / \mathrm{Nm}^{3}$ (mikrogram per normal meter kubik).

\section{Definisi Operasional}

1. Karbon monoksida (CO) adalah gas pencemar primer yang dapat mengganggu metabolisme otot dan fungsi enzim intraseluler. Sumbernya antara lain dari pembakaran sampah domestik dan berbagai aktivitas industri seperti industri logam, industri gas kimia, dan industri bahan bakar.

2. Sulfur dioksida $\left(\mathrm{SO}_{2}\right)$ adalah gas pencemar primer yang merupakan bagian dari gugus pencemar $\mathrm{SO}_{\mathrm{x}}$. Sumber pencemaran $\mathrm{SO}_{\mathrm{x}}$ berasal dari pembakaran arang, minyak bakar gas, kayu, dan aktivitas industri seperti pemurnian petroleum, dan peleburan baja.

3. Nitrogen dioksida $\left(\mathrm{NO}_{2}\right)$ adalah gas pencemar primer yang empat kali lebih berbahaya dibandingkan NO. Sumbernya berasal dari kendaraan bermotor, kegiatan industri, PLTU, dan pembakaran sampah.

4. Ozon $\left(\mathrm{O}_{3}\right)$ adalah gas pencemar sekunder yang dihasilkan dari proses fotokimia antara sinar matahari dan komponen pencemar primer[26].

Baku mutu kualitas udara ambien nasional berdasarkan Peraturan Pemerintah RI no 41 Tahun 1999, yaitu :

1. Parameter $\mathrm{CO}_{2}$ dalam waktu pengukuran 24 jam sebesar $10000 \mu \mathrm{g} / \mathrm{Nm}^{3}$.

2. Parameter $\mathrm{SO}_{2}$ dalam waktu pengukuran setahun sebesar $60 \mu \mathrm{g} / \mathrm{Nm}^{3}$.

3. Parameter $\mathrm{NO}_{2}$ dalam waktu pengukuran setahun sebesar $100 \mu \mathrm{g} / \mathrm{Nm}^{3}$.

4. Parameter $\mathrm{SO}_{2}$ dalam waktu pengukuran setahun $50 \mu \mathrm{g} / \mathrm{Nm}^{3}$

\section{Metode Penelitian dan Langkah Pengerjaan}

Penelitian ini dilakukan dengan menggunakan metode fuzzy c-means clustering. Adapun proses analisis yang dilakukan dalam penelitian ini meliputi langkah-langkah berikut:

1. Melakukan analisis deskriptif terhadap variabel penelitian yang meliputi nilai ratarata, nilai minimum, dan nilai maksimum.

2. Menghitung korelasi antar variabel penelitian.

3. Mendeteksi keberadaan outlier dalam data di setiap variabel penelitian. 
4. Melakukan pengelompokan wilayah provinsi DIY berdasarkan variabel penelitian dengan metode fuzzy c-means clustering.

5. Menginterpretasi hasil pengelompokan.

\section{PEMBAHASAN}

\section{Profile Data}

Berdasarkan Tabel 4.1, kadar CO, $\mathrm{SO}_{2}, \mathrm{NO}_{2}$, dan $\mathrm{O}_{3}$ terendah berada pada titik-titik wilayah permukiman/dusun di wilayah Bantul. Sedangkan untuk kadar tertinggi berada pada titik perempatan jalan, training camp, kampus fakultas teknik, dan industri. Perempatan jalan Wojo merupakan salah satu jalan utama untuk akses dari Kota Yogyakarta ke Bantul yang seringkali dipadati oleh kendaraan terutama saat waktu akhir pekan (Dishub Bantul). Pada industri Aneka Sinendo menjadi titik wilayah dengan kadar CO tertinggi dikarenakan sebagai industri arang briket tentu akan menimbulkan polusi udara sebagai hasil dari limbah aktivitas industrinya.

Tabel 4.1 Gambaran Umum Kualitas Udara Ambien Menurut Jenis Polutan

\begin{tabular}{|c|c|c|c|c|}
\hline & $\begin{array}{c}\operatorname{Min}(\mu g / \\
\left.\quad N m^{3}\right)\end{array}$ & $\begin{array}{c}\operatorname{Max} \\
\left(\mu g / \mathrm{Nm}^{3}\right)\end{array}$ & $\begin{array}{c}\text { Med } \\
(\mu g / \\
\left.N^{3}\right)\end{array}$ & $\begin{array}{c}\text { Mean } \\
(\mu g / \\
\left.N^{3}\right)\end{array}$ \\
\hline $\mathrm{NO}_{2}$ & $\begin{array}{c}\text { 13,19 } \\
\text { (Masjid Al } \\
\text { Masur, } \\
\text { Desa } \\
\text { Bangunjiw } \\
\text { o, Bantul) }\end{array}$ & $\begin{array}{c}\text { 59,27 } \\
\text { (Joglo } \\
\text { Boxing } \\
\text { Camp, } \\
\text { Kota } \\
\text { Yogyakarta } \\
\text { ) }\end{array}$ & 28,32 & 29,23 \\
\hline $\mathrm{SO}_{2}$ & $\begin{array}{c}\text { 14,16 } \\
\text { (Dusun } \\
\text { Kec. } \\
\text { Bantul) }\end{array}$ & $\begin{array}{c}\text { 75,66 } \\
\text { (Perempata } \\
\text { n Wojo, } \\
\text { Ring road } \\
\text { selatan } \\
\text { Kota }\end{array}$ & 32,93 & 35,36 \\
\hline
\end{tabular}

\begin{tabular}{|c|c|c|c|c|}
\hline & & $\begin{array}{c}\text { Yogyakarta } \\
\text { ) }\end{array}$ & & \\
\hline $\mathrm{CO}$ & $\begin{array}{c}174,1 \\
\text { (Dusun } \\
\text { Kec. } \\
\text { Bantul) }\end{array}$ & $\begin{array}{c}1484,3 \\
\text { (Sebelah } \\
\text { barat PT } \\
\text { Aneka } \\
\text { Sinendo) }\end{array}$ & 711,9 & 695,7 \\
\hline $\mathbf{O}_{3}$ & $\begin{array}{c}7,44 \\
\text { (SD Inpres } \\
\text { Sawit, } \\
\text { Dusun } \\
\text { Panggungh } \\
\text { arjo, } \\
\text { Bantul) }\end{array}$ & $\begin{array}{c}42,70 \\
\text { (Fakultas } \\
\text { Teknik } \\
\text { UGM) }\end{array}$ & 23,96 & 23,02 \\
\hline
\end{tabular}

Sumber data: Kementerian Lingkungan Hidup Provinsi DIY tahun 2018, diolah.

Median digunakan sebagai ukuran pemusatan karena data penelitian terdapat outlier. Median zat $\mathrm{NO}_{2}$ sebesar $28.32 \mu \mathrm{g} / \mathrm{Nm}^{3}$ masih cukup jauh dari batas nilai baku mutu $\mathrm{NO}_{2}$ pengukuran per tahun sebesar $100 \mu \mathrm{g} / \mathrm{Nm}^{3}$. Pada Median zat $\mathrm{SO}_{2}$ sebesar $32.93 \mu \mathrm{g} / \mathrm{Nm}^{3}$ masih berada setengah dari baku mutu sebesar $60 \mu \mathrm{g} / \mathrm{Nm}^{3}$. Pada median $\mathrm{O}_{3}$ sebesar $23.96 \mu \mathrm{g} / \mathrm{Nm}^{3}$ masih sekitar setengah dari batas nilai baku mutu. Jika berdasarkan ukuran pemusatan, titik-titik wilayah masih jauh dari batas baku mutu. Tetapi apabila melihat dari nilai maksimum kadar zat $\mathrm{NO}_{2}$, dan $\mathrm{O}_{3}$ hampir mendekati batas nilai baku mutu tetapi untuk zat $\mathrm{SO}_{2}$ sudah melewati batas baku mutu pengukuran per tahun.

Tabel 4.2 Boxplot dari $\mathrm{CO}, \mathrm{SO}_{2}, \mathrm{NO}_{2}$, dan $\mathrm{O}_{3}$

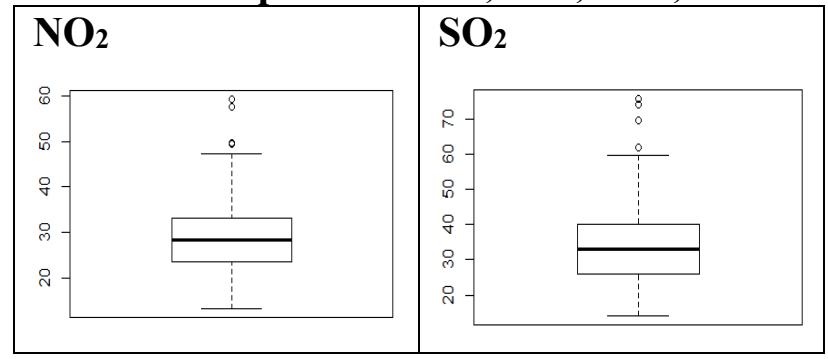




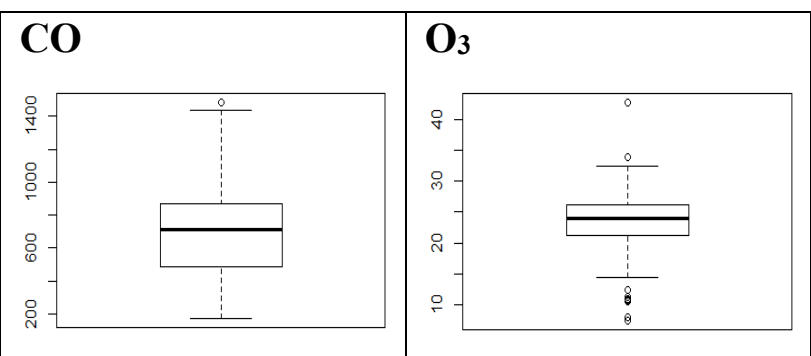

Dari gambar Tabel 4.2 di atas, kita dapat menentukan beberapa ukuran statistik. Dari badan boxplot $\mathrm{NO}_{2}$ menunjukkan sebaran data tidak simetris, tapi menjulur ke arah kanan (positively skewness). Kemudian, pada badan boxplot $\mathrm{SO}_{2}$ dapat dilihat sebaran data tidak simetris, tapi menjulur ke arah kanan (positively skewness). Pada boxplot CO sebaran datanya tidak simetris, cenderung menjulur ke arah kanan (positively skewness). Untuk boxplot $\mathrm{O}_{3}$ dapat dilihat sebaran data cenderung simetris. Untuk keempat variabel semuanya memiliki outlier (pencilan).

Oleh karena itu, sebelum mengolah data dilakukan standarisasi data (scalling data) sebagai salah satu cara mengatasi pencilan.

\section{Korelasi Antar Variabel}

Tabel 4.3 Matriks Korelasi $\mathrm{CO}, \mathrm{SO}_{2}, \mathrm{NO}_{2}$, dan $\mathrm{O}_{3}$

\begin{tabular}{|l|l|l|l|l|}
\hline & $\mathbf{N O}_{2}$ & $\mathbf{S O}_{\mathbf{2}}$ & $\mathbf{C O}$ & $\mathbf{O}_{\mathbf{3}}$ \\
\hline $\mathbf{N O}_{\mathbf{2}}$ & 1,0000 & 0,3771 & 0,1875 & 0,2461 \\
\hline $\mathbf{S O}_{2}$ & 0,3771 & 1,0000 & 0,2858 & 0,4297 \\
\hline $\mathbf{C O}$ & 0,1875 & 0,2858 & 1,0000 & 0,4174 \\
\hline $\mathbf{O}_{3}$ & 0,2461 & 0,4297 & 0,4174 & 1,0000 \\
\hline
\end{tabular}

Berdasarkan matriks korelasi pada Tabel 4.3 di atas, diperoleh nilai korelasi antar variabel kurang dari 0,5. Menurut Gujarati (2003) menyebutkan jika nilai korelasi melebihi 0,8 maka hal itu menandakan terjadi multikolinearitas. sehingga dapat dikatakan tidak terjadi pelanggaran asumsi non multikolinearitas.

\section{Penentuan Jumlah Kelompok}

Tabel 4.4 Indeks Validitas Kelompok

\begin{tabular}{|c|c|c|c|c|c|}
\hline $\begin{array}{c}\text { Jumlah } \\
\text { Kelompok }\end{array}$ & FSI & PE & PC & MPC & XBI \\
\hline 2 & 0,8052 & 0,2504 & 0,8517 & 0,7034 & 0,0998 \\
\hline 3 & 0,8525 & 0,3266 & 0,8272 & 0,7408 & 0,1845 \\
\hline 4 & 0,8302 & 0,4257 & 0,7831 & 0,7109 & 0,0683 \\
\hline 5 & 0,8141 & 0,4499 & 0,7757 & 0,7196 & 0,0888 \\
\hline 6 & 0,8344 & 0,4606 & 0,7840 & 0,7408 & 0,0818 \\
\hline
\end{tabular}

Untuk mengetahui nilai $\mathrm{k}$ optimum dalam clustering, diperlukan clustering validity index, yaitu partition coefficient, modified partition coefficient, dan fuzzy silhouette index yang bernilai tinggi, serta partition entropy, dan xiebeni index bernilai rendah. Berdasarkan rekomendasi $\mathrm{Wu}$ (2012), nilai $\mathrm{m}$ optimum berkisar 1.5 hingga 4 untuk memberikan efek robust pada data yang mengandung outlier seperti data penelitian ini. Berdasarkan output tabel di atas diperoleh fuzzifier sebesar 2 dengan banyak kelompok yang digunakan sebanyak dua.

\section{Kelompok yang Terbentuk Cluster plot}

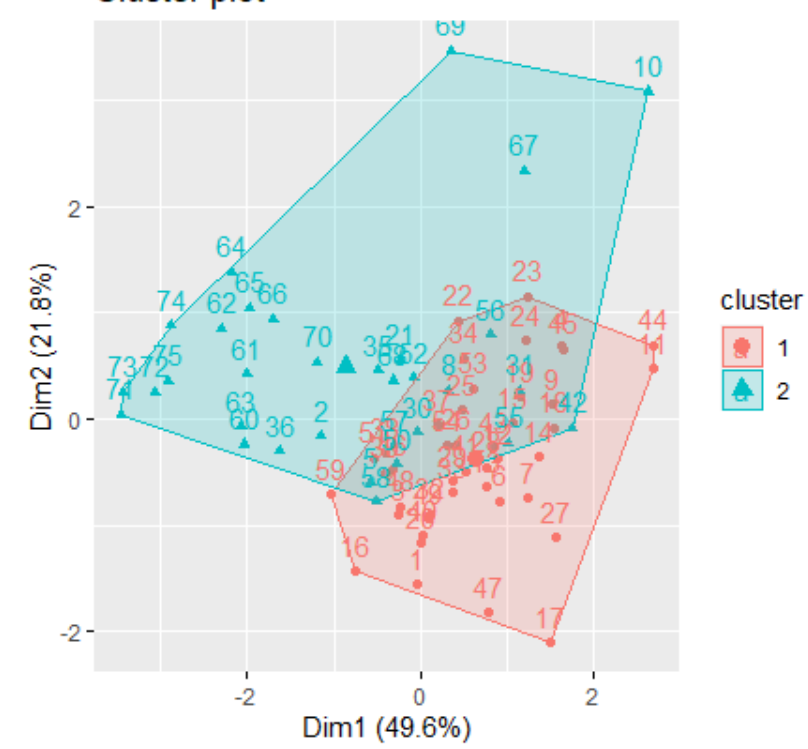

Gambar 1. Cluster Plot Sebelum Standarisasi Data 


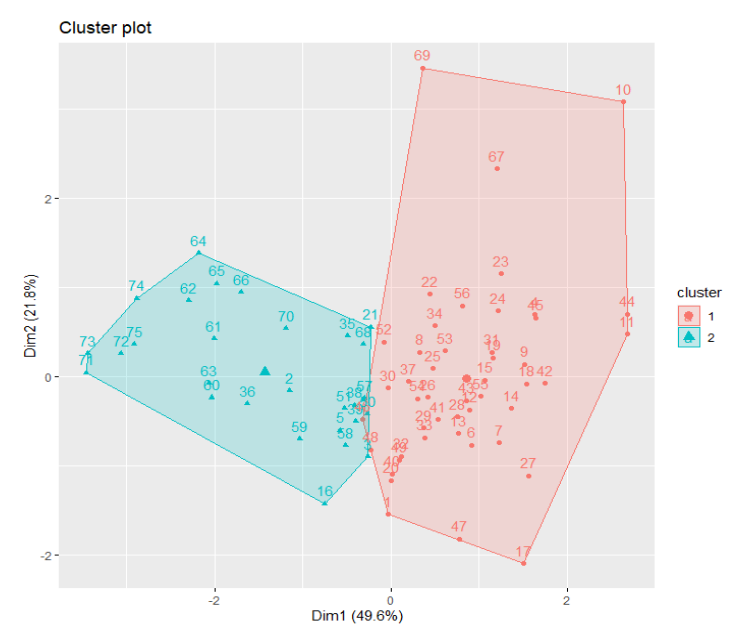

Gambar 2. Cluster Plot Setelah Standarisasi Data

Pada Gambar 1, digambarkan sebaran titik amatan berdasarkan kelompok. Pengelompokan didasarkan pada jarak terdekat titik amatan dengan nilai tengah (centroid) kelompok. Berdasarkan gambar tersebut, terdapat bagian kelompok satu dan kelompok dua yang nampak tumpang tindih. Hal ini disebabkan karena jarak amatan pada masingmasing kelompok dengan titik tengah kelompok ada yang hanya berbeda tipis, sehingga ada beberapa amatan yang tampak tumpang tindih berada di antara kelompok satu dan kelompok dua.

Untuk mengatasi kelompok yang tumpang tindih atau adanya irisan antar kelompok dilakukan standarisasi data sebagai cara juga untuk mengatasi data yang terdapat outlier pada data penelitian. Pada gambar 2 menunjukkan kelompok satu anggota kelompok relatif menyebar karena terdapat beberapa titik amatan yang nilainya cukup jauh dengan anggota lain, sedangkan kelompok dua cenderung mengelompok.

Berdasarkan cluster plot setelah standarisasi data diperoleh kelompok 1 terdiri atas 45 anggota yang Sebagian besar merupakan titik wilayah industry dan pusat keramaian (aktivitas).

\begin{tabular}{|l|l|}
\hline Industri & $\begin{array}{l}\text { Sebelah Timur PT Jogjatex, } \\
\text { Sebelah Utara PT Jogjatex, Sebelah }\end{array}$ \\
& $\begin{array}{l}\text { Selatan PT Jogjatex, Halaman PT } \\
\text { Jogjatex, Halaman PT Madu Baru, } \\
\text { Depan GKBI Medari, PC GKBI }\end{array}$ \\
\hline
\end{tabular}

\begin{tabular}{|c|c|}
\hline & $\begin{array}{l}\text { Medari, Sebelah Utara PC GKBI } \\
\text { Medari, Sebelah Timur PC GKBI } \\
\text { Medari, Sebelah Selatan PC GKBI } \\
\text { Medari, Sebelah Barat PC GKBI } \\
\text { Medari, PT Aneka Sinendo, } \\
\text { Sebelah Barat PT Aneka Sinendo, } \\
\text { Sebelah Utara PT Aneka Sinendo, } \\
\text { dan Sebelah Timur PT Aneka } \\
\text { Sinendo. }\end{array}$ \\
\hline $\begin{array}{l}\text { Persimpangan } \\
\text { Jalan }\end{array}$ & $\begin{array}{l}\text { Simpang Empat Ngelang, Pertigaan } \\
\text { Teteg/Simpang Tiga, Perempatan } \\
\text { Gose, Perempatan Druwo, } \\
\text { Perempatan Mirota Kampus, } \\
\text { Perempatan Gading, Simpang } \\
\text { Empat Siyono, Perempatan RSUD } \\
\text { Wonosari., Perempatan Janti, dan } \\
\text { Perempatan Denggung }\end{array}$ \\
\hline $\begin{array}{l}\text { Pusat } \\
\text { Keramaian }\end{array}$ & $\begin{array}{l}\text { Terminal Wates, Terminal } \\
\text { Wonosari, Depan Pasar Sepeda Jl. } \\
\text { Menteri Supeno, Depan RS PKU } \\
\text { Muhammadiyah Yogyakarta, dan } \\
\text { Depan Pasar Beringharjo. }\end{array}$ \\
\hline Perkantoran & $\begin{array}{l}\text { Depan Kantor Hotel Tentrem, } \\
\text { Depan Kantor Kecamatan Getis, } \\
\text { Depan Mirota Godean, Depan } \\
\text { TVRI, Depan Kantor Merapi Golf, } \\
\text { Depan Kantor Kec. Jetis. }\end{array}$ \\
\hline $\begin{array}{l}\text { Penginapan dan } \\
\text { Permukiman }\end{array}$ & $\begin{array}{l}\text { Depan Hotel Shapir, Hotel } \\
\text { Matahari Jl. Parang Tritis, Perum } \\
\text { Nogotirto II, dan Asrama Susteran } \\
\text { Cab. Gejayan. }\end{array}$ \\
\hline Lainnya & $\begin{array}{l}\text { Samping Rumah Bpk. Budi Pawiro, } \\
\text { Depan rumah Bpk. Santosa, Ruko } \\
\text { Janti, Depan UPN Seturan, Fakultas } \\
\text { Teknik UGM, dan Kompleks } \\
\text { Makam Tompeyan. }\end{array}$ \\
\hline
\end{tabular}

Kelompok 2 terdiri atas 30 anggota yang sebagian merupakan titik wilayah permukiman 


\begin{tabular}{|c|c|}
\hline Permukiman & $\begin{array}{l}\text { Rumah Bapak Santosa, Perumahan } \\
\text { Fakultas Teknik UGM, Rumah Jalan } \\
\text { Sabirin No. 22, Bending Sukunan, } \\
\text { Depan Rumah Bapak Slamet, Depan } \\
\text { Asrama Rohadi Oesman, Depan } \\
\text { Rumah Bapak Wardani, Samping } \\
\text { Perumahan Kehakiman, Dusun } \\
\text { Tersan, Rumah Bu Yumiati, RT } 6 \\
\text { Padukuhan } 6 \text { Nglebang, Perum } \\
\text { Nogotirto II, dan RT } 2 \text { RW } 15 \\
\text { Balong Lor. }\end{array}$ \\
\hline Industri & $\begin{array}{l}\text { Sebelah Barat PT. Jogjatex, Sebelah } \\
\text { Utara PT. Madu Baru, Sebelah } \\
\text { Timur PT. Madu Baru, Sebelah } \\
\text { Selatan PT. Madu Baru, Sebelah } \\
\text { Barat PT. Madu Baru, Sebelah } \\
\text { Selatan PT. Aneka Sinendo. }\end{array}$ \\
\hline $\begin{array}{l}\text { Persimpangan } \\
\text { Jalan }\end{array}$ & $\begin{array}{lrrr}\text { Simpang Tiga } & \text { Toyan dan } \\
\text { Perempatan Janti. } & & \end{array}$ \\
\hline Toko & $\begin{array}{l}\text { Depan Toko Besi Dongkelan dan } \\
\text { Depan Ruko Bayeman. }\end{array}$ \\
\hline Lainnya & $\begin{array}{l}\text { Depan Kampus STTL, Depan } \\
\text { Kantor Kecamatan Patuk, Depan } \\
\text { Hotel Shapir, Utara Hotel Shapir, } \\
\text { Joglo Boxing Premiere Camp, } \\
\text { Masjid Al-Mansur, Depan UPN } \\
\text { Seturan dan Utara SD Inpres Sawit. }\end{array}$ \\
\hline
\end{tabular}

\section{Pairs Plot}

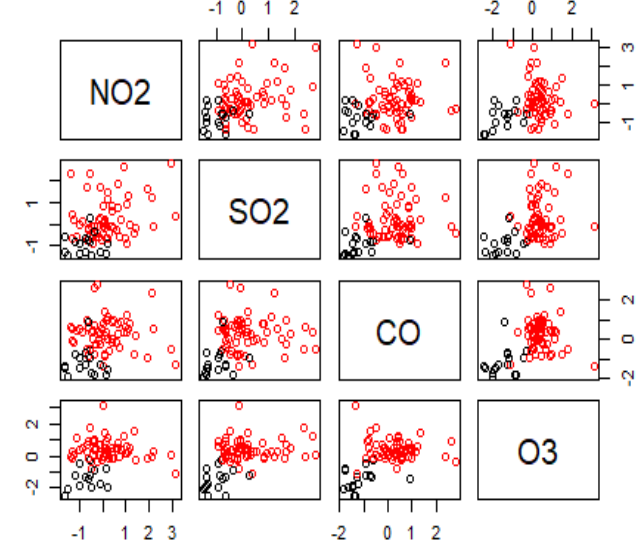

Gambar 3. Pairs Plot CO, $\mathrm{SO}_{2}, \mathrm{NO}_{2}$, dan $\mathrm{O}_{3}$
Pada pairs plot, terlihat bahwa kelompok satu (warna merah) merupakan kelompok titik amatan yang memiliki $z$-score $\mathrm{NO}_{2}$ dalam rentang -1 sampai 1 dan kelompok dua (warna hitam) merupakan kelompok titik amatan yang memiliki $z$-score $\mathrm{NO}_{2}$ dalam rentang -1 sampai 3. Hal ini dapat diartikan bahwa kelompok satu merupakan kompok titik amatan dengan kadar $\mathrm{NO}_{2}$ lebih tinggi dibandingkan kelompok dua. Masingmasing variabel yang dikombinasikan dengan $\mathrm{NO}_{2}$ menunjukkan hasil bahwa kelompok satu merupakan kelompok titik amatan dengan kadar $\mathrm{SO}_{2}$ lebih tinggi, kadar $\mathrm{CO}$ lebih tinggi, dan kadar $\mathrm{O}_{3}$ lebih tinggi dibandingkan kelompok titik amatan yang ada di kelompok dua. Interpretasi pada $\mathrm{NO}_{2}$ tersebut sejalan dengan dengan hasil pada $\mathrm{SO}_{2}, \mathrm{CO}$, dan $\mathrm{O}_{3}$

Dari penjabaran pairs plot di atas, diketahui bahwa kelompok satu merupakan kelompok titik amatan dengan kadar $\mathrm{NO}_{2}, \mathrm{SO}_{2}, \mathrm{CO}$, dan $\mathrm{O}_{3}$ yang lebih tinggi dibandingkan titik amatan yang berada pada kelompok dua. Ini sejalan dengan titik centroid yang dihasilkan oleh masingmasing kelompok.

\section{KESIMPULAN}

Berdasarkan hasil analisis profile data sebelum dilakukan pengelompokan diperoleh kadar CO, $\mathrm{SO}_{2}, \mathrm{NO}_{2}$, dan $\mathrm{O}_{3}$ terendah berada pada titik-titik wilayah permukiman/dusun di wilayah Bantul. Sedangkan untuk kadar tertinggi berada pada titik perempatan jalan, training camp, kampus fakultas teknik, dan industri. Berdasarkan ukuran pemusatan, titik-titik wilayah masih jauh dari batas baku mutu. Tetapi apabila melihat dari nilai maksimum kadar zat $\mathrm{NO}_{2}$, dan $\mathrm{O}_{3}$ hampir mendekati batas nilai baku mutu dan untuk zat $\mathrm{SO}_{2}$ sudah melewati batas baku mutu pengukuran per tahun.

Selanjutnya dilakukan pengelompokan dengan hasil perbandingan clustering validity index 
diperoleh nilai fuzzifier sebesar dua dengan dua kelompok. Sehingga pengkelompokan titik-titik wilayah pemantauan udara provinsi D.I Yogyakarta dengan metode Fuzzy C-Means berdasarkan variabel kadar $\mathrm{NO}_{2}, \mathrm{SO}_{2}, \mathrm{CO}$, dan $\mathrm{O}_{3}$ diperoleh dua kelompok dengan jumlah keanggotaan kelompok pertama sebanyak 45 titik wilayah yang sebagian besar terdiri dari titik wilayah industri, persimpangan jalan, dan pusat keramaian. Sedangkan kelompok kedua sebanyak 30 titik wilayah yang sebagian besar didominasi titik wilayah permukiman. Titik centroid kelompok satu untuk semua variabel kadar $\mathrm{NO}_{2}, \mathrm{SO}_{2}, \mathrm{CO}$, dan $\mathrm{O}_{3}$ lebih tinggi dibanding kelompok dua. Hal tersebut mengindikasikan bahwa pada kelompok kedua merupakan titik-titik wilayah yang rawan akan peningkatan polusi udara yang diakibatkan keempat zat tersebut. Pada kelompok dua titik centroid keempat variablel lebih rendah daripada kelompok pertama yang mengindikasikan bahwa titik amatan pada wilayah permukiman memiliki kadar keempat zat pencemar tersebut yang rendah.

\section{KRITIK DAN SARAN}

Berdasarkan hasil pemetaan pada Gambar 3, pemantauan kualitas udara ambien di Provinsi Yogyakarta menunjukkan titik pengukuran banyak terdapat di Kota Yogyakarta dibandingkan Kabupaten lainnya. Akan lebih baik menambah titik wilayah pengukuran yang mewakili setiap Kawasan (industri, perumahan, padat lalu lintas, dst.) di setiap kabupaten/kota supaya lebih merata untuk mewakili kabupaten/kota masing-masing dalam pengukuran kualitas udara.

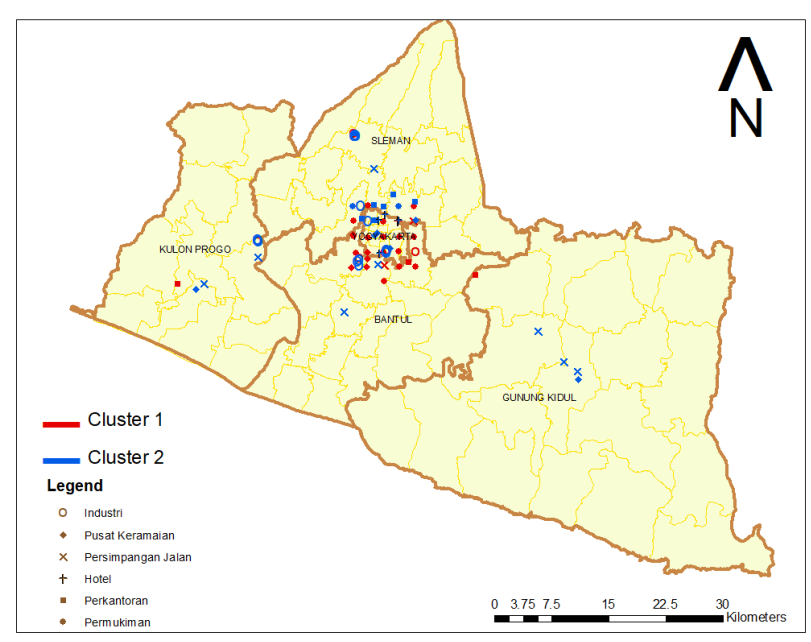

Gambar 4. Persebaran kelompok yang terbentuk di Provinis DIY 2018.

Hasil pengkelompokan juga menunjukkan bahwa pemerintah Yogyakarta sudah cukup baik dalam penanganan kualitas udara. Kelompok satu merupakan kawasan rawan polusi dengan titik wilayah kelompok tersebut merupakan industri, persimpangan jalan, tempat umum (terminal, gedung, rumah sakit). Hal ini mengindikasikan bahwa persimpangan jalan pada kelompok satu tinggi akan keempat zat polutan karena seringkali padat kendaraan bermotor. Untuk mengurangi penumpukan kendaraan di jalan dapat dilakukan kebijakan seperti ganjil-genap pada jalan-jalan tertentu supaya arus kendaraan dapat tersebar dan tidak berkumpul pada satu tempat yang dapat meningkatkan kadar polutan pada jam-jam tertentu. Selain itu, wilayah industri di kelompok ini juga perlu diperhatikan pembuangan limbah udaranya dikarenakan kadar dari $\mathrm{SO}_{2}$ di titik wilayah tertentu yang hampir mencapai baku mutu per tahun.

Sedangkan kelompok dua yang dominan permukiman rendah akan kadar polutan sehingga warga setempat aman dari kontaminasi polutan yang berefek pada kesehatan. Selain itu, kelompok dua juga terdapat 6 titik wilayah industri yang menandakan bahwa kawasan industri juga memiliki sisi yang aman untuk para 
pegawainya dari polutan udara hasil limbah industri.

\section{DAFTAR PUSTAKA}

[1] Bappeda Provinsi D.I. Yogyakarta. 2014. Polusi Udara dan Uji Emisi Gas Buang Kendaraan Bermotor sebagai Prasyarat Pemberian Perpanjangan STNK.

[2] Kementrian Lingkungan Hidup dan Kehutanan RI. 2017. Laporan Kinerja 2017. Direktorat Jenderal Pengendalian Pencemaran dan Kerusakan Lingkungan: Jakarta.

[3] Kementrian Lingkungan Hidup dan Kehutanan RI. 2018. Laporan Kinerja 2018. Direktorat Jenderal Pengendalian Pencemaran dan Kerusakan Lingkungan: Jakarta.

[4] Badan Pusat Statistik. "Kepadatan Penduduk Menurut Provinsi, 2000-2015" [Tabel Dinamis]. Diunduh dari https://www.bps.go.id/linkTableDinamis/ view/id/842.

[5] Dinas Lingkungan Hidup Kota Yogyakarta. 2018. Laporan Analisa Hasil Pemantauan Kualitas Udara di Kota Yogyakarta.

[6] Tribunjogja.com (2019). "Kualitas Udara di Kota Yogyakarta Masih Baik, Namun Polusi Dapat Meningkat Saat Liburan". Diunduh dari https://jogja.tribunnews.com/2019/08/04/k ualitas-udara-di-kota-yogyakarta-masihbaik-namun-polusi-bisa-meningkat-saatliburan.

[7] Zuhri, M.S. (2014). Pengaruh Faktor-faktor Demografi Terhadap Emisi Udara di Indonesia. Jurnal Ilmu Ekonomi dan Pembangunan, Vol. 14 (2), 13-37.

[8] Rosdiyansyah, F. (2017). K-Means dan Fuzzy C-Means Pada Analisis Data Polusi Udara di Kota X. Seminar Nasional Teknologi Informasi dan Multimedia, Vol. 5 (1).

[9] Badan Pusat Statistik. 2014. Statistik Transportasi Darat. Badan Pusat Statistik: Jakarta.

[10] Badan Pusat Statistik. 2016. Statistik Transportasi Darat. Badan Pusat Statistik: Jakarta.
[11] Badan Pusat Statistik. 2018. Statistik Transportasi Darat. Badan Pusat Statistik: Jakarta.

[12] Damiyanti, dkk (2003). Pencemaran Udara di Ruang Proses Pembatikan Industri Rumah Tangga Batik (Studi Kasus: Industri Rumah Tangga di Kampung Taman Kotamadya Yogyakarta). Jurnal Manusia dan Lingkungan Universitas Gajah Mada, Vol. 10 (1), 19-32.

[13] Radar Jogja. 2016. Asap Pabrik Aspal Masih Mengepul, Pemerintah Kabupaten Sleman Angkat Tangan.

[14] Efiyah, Uum. 2014. Penerapan Algoritma Fuzzy C-Means untuk Pengelompokan Harga Gabah di Tingkat Penggilingan Berdasarkan Kualitas Gabah [Skripsi], Fakultas Sains dan Teknologi, Universitas Islam Negeri Maulana Malik Ibrahim.

[15] Sitepu, R, dkk (2011). Analisis Cluster terhadap Tingkat Pencemaran Udara pada Sektor Industri di Sumatera Selatan. Jurnal Penelitian Sains, Vol. 13 (3), 11-17.

[16] Ningrum, F, dkk (2011). Fuzzy C-Means Clustering dengan Analisis Robust. Seminar Nasional Statistika 12 November 2011.

[17] Tan, P.N., Steinbach, M., Kumar, V. 2006. Introduction to Data Mining. Pearson Education, Inc.

[18] Nooraeni, R. (2015). Cluster Method Using A Combination Of Cluster Kprototype Algorithm And Genetic Algorithm For Mixed Data. Jurnal Aplikasi Statistika \& Komputasi Statistik, Vol. 7 (2), 81-98.

[19] Pramana, S., dkk. 2018. Data Mining dengan R: Konsep dan Implementasinya. In Media, Jakarta.

[20] Wu, K.L. \& Yang, M.S.(2005). A Cluster Validity Index For Fuzzy Clustering. Taiwan: Pattern Recognition Letters, Vol. 26.

[21] Haqiqi, B.N. \& Kurniawan, R.(2015). "Analisis Perbandingan Metode Fuzzy CMeans Dan Subtractive Fuzzy C-Means". Diunduh dari https://www.researchgate.net/publication/ 291832481 ANALISIS PERBANDING AN_METODE_FUZZY_C- 
MEANS_DAN_SUBTRACTIVE_FUZZ Y_C-MEANS

[22] Mashfuufah, S., Deden I. (2018). Penerapan Partition Entropy Index, Partition Coefficient Index dan Xie Beni Index untuk Penentuan Jumlah Kelompok Optimal pada Algoritma Fuzzy C-Means dalam Pemetaan Tingkat Kesejahteraan Penduduk Jawa Tengah. The $7^{\text {th }}$ URECOL STIKES PKU Muhammadiyah Surakarta.

[23] Sormin, R. P. A., dkk. (2015). Aplikasi Metode Fuzzy C-Means Untuk Pengkelompokan Kelayakan Rumah Di Desa Wayame, Ambon. Jurnal Ilmu Matematika dan Terapan. Vol 9 (2), 135146.

[24] Khairati, A. F., dkk (2019). Kajian Indeks Validitas pada Algoritma K-Means Enhanced dan K-Means MMCA. PRISMA Prosiding Seminar Nasional Matematika 2. 161-170.

[25] Muchsin, A.K., Sudarma, M. (2015). Penerapan Fuzzy C-Means Untuk Penentuan Besar Uang Kuliah Tunggal Mahasiswa Baru. Lontar Komputer. Vol 6 (3), 175-184.

[26] Keputusan Gubernur Provinsi Daerah Istimewa Yogyakarta Nomor 153 Tahun 2002 Tentang Baku Mutu Udara Ambien Daerah di Provinsi Daerah Istimewa Yogyakarta. 